\title{
Identification of a cyclin B1-derived CTL epitope eliciting spontaneous responses in both cancer patients and healthy donors
}

\author{
Rikke Sick Andersen • Rikke Bak Sørensen • \\ Cathrin Ritter • Inge Marie Svane · Jürgen C. Becker • \\ Per thor Straten • Mads Hald Andersen
}

Received: 2 February 2010/Accepted: 18 September 2010/Published online: 28 October 2010

(C) The Author(s) 2010. This article is published with open access at Springerlink.com

\begin{abstract}
With the aim to identify cyclin B1-derived peptides with high affinity for HLA-A2, we used three in silico prediction algorithms to screen the protein sequence for possible HLA-A2 binders. One peptide scored highest in all three algorithms, and the high HLA-A2-binding affinity of this peptide was verified in an HLA stabilization assay. By stimulation with peptide-loaded dendritic cells a CTL clone was established, which was able to kill two breast cancer cell lines in an HLA-A2-dependent and peptide-specific manner, demonstrating presentation of the peptide on the surface of cancer cells. Furthermore, blood from cancer patients and healthy donors was screened for spontaneous T-cell reactivity against the peptide in IFN- $\gamma$ ELISPOT assays. Patients with breast cancer, malignant melanoma, or renal cell carcinoma hosted powerful and high-frequency T-cell responses against the peptide. In addition, when blood from healthy donors was tested, similar responses were observed. Ultimately, serum from cancer patients and healthy donors was analyzed for anticyclin B1 antibodies. Humoral responses against cyclin B1 were frequently detected in both cancer patients and
\end{abstract}

R. S. Andersen ( $\square)$ · R. B. Sørensen · I. M. Svane

P. thor Straten - M. H. Andersen

Department of Hematology, 54P4,

Center for Cancer Immune Therapy (CCIT),

University Hospital Herlev, Herlev Ringvej 75,

2730 Herlev, Denmark

e-mail: risian01@heh.regionh.dk

C. Ritter · J. C. Becker

Department of Dermatology, University of Graz,

Auenbruggerplatz 8, 8036 Graz, Austria

I. M. Svane

Department of Oncology, University Hospital Herlev,

Herlev Ringvej 75, 2730 Herlev, Denmark healthy donors. In conclusion, a high-affinity cyclin B1derived HLA-A2-restricted CTL epitope was identified, which was presented on the cell surface of cancer cells, and elicited spontaneous $\mathrm{T}$-cell responses in cancer patients and healthy donors.

Keywords Cyclin B1 - Tumor-associated antigen . Cytotoxic T cells - Anti-cancer vaccination - CTL epitope

\section{Introduction}

It is well established that tumor cells express tumor-associated antigens (TAAs), and that TAA-derived peptides are presented in context of human leukocyte antigen (HLA) molecules and recognized by $\mathrm{T}$ cells. A high number of TAAs have been characterized and cytotoxic T-lymphocyte (CTL) epitopes from these identified [1]. Several of these epitopes have been tested in clinical vaccination trials, and some promising clinical responses have been observed [2-4]. Nevertheless, clinical responses remain infrequent; thus, therapeutic anti-cancer vaccination has not yet met its promise. One reason is the ability of cancer cells to escape the immune system by loss or down-regulation of antigens [5]. To this end, targeting of TAAs important for survival and growth of tumor cells (such as for example survivin [6] and telomerase [7]) may minimize the risk of tumor immune escape.

Cyclin B1 is one of the key regulators of the cell cycle, regulating the transition from $\mathrm{G}_{2}$ to $M$ phase in complex with the cyclin-dependent protein kinase cdc2. Cyclin B1 expression initiates during S-phase, peaks at $\mathrm{G}_{2} / \mathrm{M}$ phase, and at the end of mitosis cyclin B1 is rapidly degraded [8]. Cyclin B1 is needed for cells to enter mitosis, and therefore essential for growth of all cells, including tumor cells. 
Thus, immune escape by down-regulation or loss of expression of cyclin B1 would impair sustained tumor cell growth. As a consequence, cyclin B1 is an attractive target for anti-cancer immune therapy.

In normal cells, cyclin B1 is expressed at almost undetectable levels; however, many tumors express high constitutive levels of cyclin B1, which causes uncontrolled tumor growth [9]. This overexpression has been observed in several human solid tumors, for example, breast cancer (BC), malignant melanoma (MM), and renal cell carcinoma (RCC) [8, 10-12], as well as some hematological cancers [13]. In normal cells, cyclin B1 is restricted to the nucleus, whereas it accumulates in the cytoplasm in tumor cells [8, 14]. This causes increased degradation by the ubiquitin pathway, which leads to increased presentation of cyclin B1-derived peptides on the surface of cancer cells compared with normal cells [8], which in turn may lead to more efficient $\mathrm{T}$-cell recognition. The overexpression of cyclin B1 as well as the cytoplasmic localisation in cancer cells compared with normal cells makes cyclin B1 a good target candidate for anti-cancer immune therapy.

The cyclin B1-derived T-cell epitopes described so far have been of low HLA-binding affinity. In the present study, a high-affinity cyclin B1-derived peptide restricted by HLA-A2 was selected using in silico peptide prediction algorithms. The predicted high binding affinity to HLA-A2 was validated experimentally, and a CTL clone was established that was able to kill cyclin B1-overexpressing $\mathrm{BC}$ cell lines in an HLA-A2-dependent and peptide-specific manner. Also, peptide-specific spontaneous $\mathrm{CD}^{+}$ $\mathrm{T}$-cell responses as well as anti-cyclin $\mathrm{B} 1$ antibody responses were observed in both healthy donors and patients with BC, MM, or RCC.

\section{Materials and methods}

Cancer patients and healthy donors

Peripheral blood lymphocytes (PBLs) from end-stage BC patients, RCC patients, and MM patients were used in the study. The PBLs were obtained from the University Hospital Herlev as leukapheresis products, depleted of monocytes (by adherence). The cells were cryopreserved at $-150^{\circ} \mathrm{C}$ in fetal calf serum (FCS; GibcoBRL) containing $10 \%$ dimethyl sulfoxide (DMSO; Sigma-Aldrich). Tissue typing was conducted at the Department of Clinical Immunology, Copenhagen University Hospital. Informed consent was obtained from the patients before any of these measures.

Blood from healthy donors was obtained from the blood bank at Copenhagen University Hospital. Peripheral blood mononuclear cells (PBMCs) were isolated by density centrifugation on Lymphoprep $^{\mathrm{TM}}$ (Axis-Shield PoC). The PBMCs were cryopreserved at $-150^{\circ} \mathrm{C}$ in $\mathrm{FCS}$ and $10 \%$ DMSO.

Serum from healthy donors (26-36 years of age) and cancer patients (36-81 years of age) was obtained from University Hospital Herlev. Blood was allowed to coagulate, spun down, and serum was removed.

\section{Cell lines}

The human T2 cell line (CRL-1992) is a hybrid of the B-lymphoblastoid cell line, B-LCL.174, and the T-lymphoblastoid cell line, T-LCL CEM. It synthesizes HLA-A2.1 and HLA-B51.1, but does not express normal amounts on the cell surface due to lack of functional transporter associated with antigen processing (TAP) heterodimers. The cell lines MDA-MB-231 (HTB-26) and CAMA-1 (HTB21) are $\mathrm{HLA}-\mathrm{A} 2^{+} \mathrm{BC}$ cell lines, and $\mathrm{ZR}-75-1$ (CRL-1500) is an HLA-A2 ${ }^{-}$BC cell line. K562 (CCL-243) is a chronic myelogenous leukemia cell line, which is $\mathrm{HLA}^{-}$and sensitive to NK-cell-mediated killing. All cell lines were purchased from American Type Culture Collection (ATCC) and cultured in RPMI 1640 medium (GibcoBRL) containing $10 \%$ FCS. All cell lines are routinely tested for mycoplasma using a PCR-based method, and the morphology is checked visually by microscope.

Peptides and peptide prediction

The Cyclin B1-derived peptide CB204 (ILIDWLVQV) and

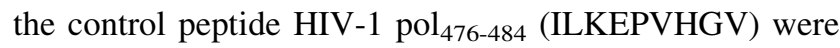
both purchased from GenScript Corporation. CB204 was selected using the in silico peptide prediction algorithms SYFPEITHI [15], NetMHC [16, 17], and BIMAS [18].

HLA stabilization assay for peptide binding to HLA class I molecules

HLA-A2-binding affinity of the CB204 peptide was carried out as described elsewhere [19, 20]; only the lysis buffer was modified from Andersen et al. (Mega-9 was excluded and the protease inhibitors used were $5 \mathrm{mM}$ iodoacetamide, $2 \mu \mathrm{g} / \mathrm{ml}$ pepstatin and $200 \mu \mathrm{g} / \mathrm{ml}$ pefabloc; Boehringer Mannheim). In short, the HLA stabilization assay is based on stabilization of HLA class I molecules after loading of different concentrations of peptide. T2 cells were metabolically labeled with $\left[{ }^{35} \mathrm{~S}\right]$-methionine (Amersham). Stably folded HLA class I molecules were immuneprecipitated and separated by isoelectric focusing (IEF) gel electrophoresis. HLA heavy chain bands were quantified using the FLA-3000 phosphorimager and the Multi Gauge V3.1 software from Fujifilm. The intensity of each band is directly related to the amount of peptide-HLA class I 
complex recovered during the assay. The recovery of HLAA2 was measured in the presence of $40,4,0.4$, and $0.04 \mu \mathrm{M}$ of the relevant peptide, and compared with the high-affinity HIV-1 pol $_{476-484}$ peptide. The experiment was performed twice, and within each experiment HLA-A2 stabilization (arbitrary units) was normalized to the HIV control containing $40 \mu \mathrm{M}$ HIV peptide.

Establishment of antigen-specific T-cell cultures and clones

Autologous dendritic cells (DCs) were used to stimulate PBLs from a RCC patient. DCs were generated from monocytes, derived from a leukapheresis product, by adherence on culture dishes at $37^{\circ} \mathrm{C}$ and $5 \% \mathrm{CO}_{2}$ for $1 \mathrm{~h} \mathrm{in}$ RPMI 1640 containing 10\% human serum (Sigma). The adherent monocytes were cultured in the presence of $250 \mathrm{U} /$ $\mathrm{ml} \mathrm{IL-4}$ and 1,000 U/ml GM-CSF (Leucomax, Shering Plough) for 6 days. Next, the DCs were matured with $10 \mathrm{ng} / \mathrm{ml} \mathrm{IL-1} \beta, 10 \mathrm{ng} / \mathrm{ml}$ IL-6, $10 \mathrm{ng} / \mathrm{ml}$ TNF- $\alpha$ (CellGenix), and $1 \mu \mathrm{g} / \mathrm{ml} \mathrm{PGE}_{2}$ (Pfizer). The phenotype of the DCs used were characteristic for mature myeloid DCs. FACS analysis showed a high expression of CD11c (100\%), CD33 (99\%), CD40 (95\%), CD54 (99\%), CD80 (83\%), CD83 (97\%), CD86 (98\%), CCR7 (71\%), HLA-A2 (100\%), and HLA-DR (98\%), and a minor expression of CD1a (1\%).

PBLs were stimulated with irradiated (25 Gy), peptideloaded autologous DCs (PBL:DC ratio $=3 \times 10^{6}: 3 \times$ $10^{5}$ ) and cultured in X-vivo medium (Bio Whittaker) with $5 \%$ human serum. The following day, $5 \mathrm{ng} / \mathrm{ml} \mathrm{IL-7} \mathrm{and}$ $100 \mathrm{pg} / \mathrm{ml} \mathrm{IL-12}$ (PeproTech) were added. After 1 week $5 \mathrm{ng} / \mathrm{ml} \mathrm{IL-7} \mathrm{was} \mathrm{added,} \mathrm{and} \mathrm{after} \mathrm{additional} 5$ days, the culture was stimulated with DCs as on day one. The next day, $5 \mathrm{ng} / \mathrm{ml} \mathrm{IL-7} \mathrm{and} 100 \mathrm{pg} / \mathrm{ml} \mathrm{IL-12}$ were added. After 1 week, the culture was stimulated with irradiated (25 Gy), peptide-loaded autologous PBLs (culture:PBL ratio $=$ $1.5 \times 10^{6}: 2 \times 10^{6}$ ), and the following day $40 \mathrm{U} / \mathrm{ml} \mathrm{IL-2}$ (PeproTech) was added. A fourth stimulation with PBLs and IL-2 was given after an additional week, and the following week the culture was tested for specificity for $\mathrm{CB} 204$ in a ${ }^{51} \mathrm{Cr}$-release assay.

The specific culture was cloned by limiting dilution in the presence of $10^{5}$ cloning mix cells and $120 \mathrm{U} / \mathrm{ml} \mathrm{IL}-2$. Cloning mix was prepared from irradiated (25 Gy) PBMCs from three healthy donors, which were mixed at a concentration of $10^{6}$ cells $/ \mathrm{ml}$ and stimulated with phytohemagglutinin (PeproTech) for $2 \mathrm{~h}$. Clones were administered $120 \mathrm{U} / \mathrm{ml} \mathrm{IL-2}$ every 3-4 days.

\section{Cytotoxicity assay}

Conventional $4 \mathrm{~h}{ }^{51} \mathrm{Cr}$-release assays for CTL-mediated cytotoxicity were carried out as described elsewhere [21].
In brief, target cells were labeled with $\mathrm{Na}_{2}^{51} \mathrm{CrO}_{4}$ (Perkin Elmer) for $1 \mathrm{~h}$, washed, and co-cultured with the effector cells for $4 \mathrm{~h}$. Next, the level of ${ }^{51} \mathrm{Cr}$ in the supernatants was measured using a Perkin Elmer Wallac Wizard 1470 automatic gamma counter. Target cells were cancer cell lines or peptide-loaded T2 cells. Lysis was inhibited in a cold target inhibition assay using unlabeled, peptide-loaded $\mathrm{T} 2$ cells. Inhibitor:target ratio was 20:1.

Subcellular fractionation of cancer cell lines and western blot

$4 \times 10^{6}$ cells were washed in PBS, pelleted, suspended in cytoplasmic lysis buffer [10 mM Hepes pH 7.5, $2 \mathrm{mM}$ $\mathrm{MgCl}_{2}, 1 \mathrm{mM}$ EDTA, $1 \mathrm{mM}$ EGTA, $1 \mathrm{mM}$ KCL, $1 \mathrm{mM}$ Dithiothreitol (DTT), $10 \mathrm{mM} \mathrm{NaF}, 1 \mathrm{mM}$ phenylmethylsulfonyl fluoride (PMSF)], and incubated for $15 \mathrm{~min}$ at $4^{\circ} \mathrm{C}$. Next, Nonidet P-40 (NP-40) was added, samples were incubated for $15 \mathrm{~min}$ at $4^{\circ} \mathrm{C}$, and centrifuged at $10,000 \times g$ for $10 \mathrm{~min}$ at $4^{\circ} \mathrm{C}$. The supernatant was harvested (cytoplasmic fraction). The pellet was suspended in nuclear lysis buffer $(20 \mathrm{mM}$ Hepes $\mathrm{pH} 7.5,500 \mathrm{mM} \mathrm{NaCl}$, $10 \%$ glycerol, $0.2 \%$ NP-40, $1 \mathrm{mM}$ DTT, $10 \mathrm{mM} \mathrm{NaF}$, $1 \mathrm{mM}$ PMSF), and centrifuged at $10,000 \times g$ for $15 \mathrm{~min}$ at $4^{\circ} \mathrm{C}$. The supernatant was harvested (nuclear fraction).

The cytoplasmic and nuclear fractions were subjected to western blotting as described previously [22]. The membrane was cut into three pieces for incubation with anticyclin B1 antibody (BD, 554176), anti-PARP antibody (nuclear loading control; Cell signaling, 9542), or antiactin antibody (cytoplasmic loading control; Sigma, A3853). To ensure equal loading, the total protein concentration of each sample was determined by Bradford Protein Assay (Bio-Rad).

\section{Interferon- $\gamma($ IFN- $\gamma)$ ELISPOT assay}

The IFN- $\gamma$ ELISPOT assay was used to quantify peptidespecific IFN- $\gamma$-releasing effector cells, as described previously [23]. Before analysis, PBMCs or PBLs were stimulated once in vitro with $20 \mu \mathrm{M}$ peptide to extend the sensitivity of the assay [24]. The following day, $40 \mathrm{U} / \mathrm{ml}$ IL-2 was added, and after 7-8 days in culture, the cells were tested for reactivity. Briefly, nitrocellulose-bottomed 96-well plates (MSIPS4 W, Millipore) were coated with anti-IFN- $\gamma$ antibody (Mabtech, 1-D1 K). The wells were washed and blocked with X-vivo medium. Effector cells were added in duplicates, at different cell concentrations $\left(1 \times 10^{5}, 3 \times 10^{5}\right.$, and $5 \times 10^{5}$ cells per well), with or without $5 \mu \mathrm{M}$ peptide. Also, $10^{4} \mathrm{~T} 2$ cells were added per well. The plates were incubated overnight. The following day, the wells were washed and incubated with biotinylated secondary antibody (Mabtech, 7-b6-1) for $2 \mathrm{~h}$. Next, the 
wells were washed, and avidin-enzyme conjugate (streptavidin-alkaline phosphatase conjugate, Mabtech) was added. The plates were incubated for $1 \mathrm{~h}$, before the wells were washed, and enzyme substrate (NBT/BCIP, Mabtech) was added. The plates were incubated at room temperature for up to $5 \mathrm{~min}$. Upon emergence of dark purple spots, the reaction was stopped by washing with tap water. The spots were counted using an ImmunoSpot ${ }^{\circledR}$ Analyzer plate reader and the software ImmunoCapture 6.0 and ImmunoSpot professional satellite 4.0 .17 (C.T.L. Cellular Technology Ltd.). The peptide-specific CTL frequency was calculated as the average number of peptide-specific spots formed in the ELISPOT assay, i.e., the number of spots formed in the wells with no added peptide, subtracted from the number of spots formed in wells with CB204. A response was defined as the average number of peptide-specific spots $\pm 1 / 2$ SD $>25$ spots per $10^{5}$ PBLs/PBMCs.

\section{Cyclin B1 ELISA}

96-well plates (Nunc, Thermo Scientific) were coated with $0.65 \mu \mathrm{g}$ of recombinant human cyclin B1 protein (Santa Cruz Biotechnology) in $50 \mu \mathrm{l}$ PBS and incubated overnight at $4^{\circ} \mathrm{C}$. Plates were washed with PBS and blocked with $2.5 \%$ BSA in PBS (blocking buffer) for $1 \mathrm{~h}$. Blocking buffer was discarded and $100 \mu \mathrm{l}$ of diluted serum was added to each well (dilution 1:200). The plates were incubated for 1 hour at room temperature and then washed with $1 \%$ Tween in PBS. Next, $100 \mu$ l anti-human IgG antibody conjugated to alkaline phosphatase (Sigma) was added to each well and the plates were incubated for 1 hour at room temperature. Plates were washed and $100 \mu \mathrm{l}$ alkaline phosphatase yellow liquid substrate (Sigma) was added. Plates were incubated 1 hour at room temperature in the dark, and the reaction was stopped with $50 \mu \mathrm{l} 3 \mathrm{M}$ $\mathrm{NaOH}$. Absorbance was read at $405 \mathrm{~nm}$. Background for each sample was measured in uncoated wells and subtracted from each sample before it was normalized to a positive control (serum from a MM patient that was found to give an absorbance of 1.35 in the ELISA).

\section{Results}

Patient characteristics

Patient samples were collected upon inclusion in four different vaccination trials [25-27]. Disease progression was a common inclusion criterion. All but one patient had received prior treatments, but no patients suffered from other malignancies. The MM patients ( $n=6$, age 36-81, 4 females, 2 males) all had metastatic disease (ranging from 5 to 229 months), and had metastases at two, three or four sites. One patient was treatment naive, but remaining five received prior treatment with electro-chemotherapy, IL-2 and INF- $\alpha$, or DC vaccination. The patients with RCC ( $n=6$, age $49-65,1$ female, 5 males) had from one to three metastases. Most of them received prior treatment with IL-2 in combination with INF- $\alpha$. BC patients from two different trials were included ( $n=10$, age 44-64). In one trial the patients $(n=4)$ had from one to six metastases. They all received prior treatment with endocrine regimes and one patient with chemotherapy as well. The other trial was quickly closed due to disease progression $(n=6)$. All patients had multiple metastases and received prior treatment with several lines of standard chemotherapy.

Peptide binding to HLA-A2

In silico peptide prediction algorithms were used to predict cyclin B1-derived peptides with high affinity for HLA-A2. The three algorithms SYFPEITHI [15], NetMHC [17], and BIMAS [18] were used, and they all predicted the peptide CB204 to bind HLA-A2 with the highest affinity compared with other cyclin B1-derived nonameric peptides. The binding affinity of the CB204 synthetic peptide was studied in an HLA stabilization assay (Fig. 1). Compared with a high-affinity HIV-derived positive control peptide, the CB204 peptide bound with very high affinity to HLA-A2.

\section{CTL killing of cancer cells}

PBLs from a RCC patient were stimulated twice with peptide-loaded autologous DCs, following two stimulations with peptide-pulsed PBMCs. The peptide-specific culture was cloned by limiting dilution. A CB204-specific clone

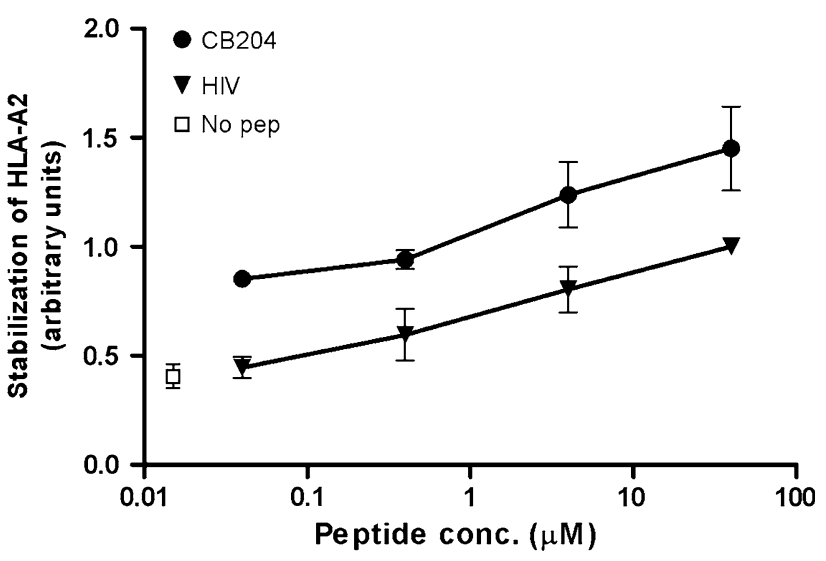

Fig. 1 Stabilization of HLA-A2 by CB204 analyzed using an HLA stabilization assay. HIV is a high-affinity peptide (HIV-1 pol ${ }_{476-484}$ ) used as positive control. CB204 stabilizes HLA-A2 to a higher degree than HIV, and therefore binds to HLA-A2 with very high affinity. The graph shows the mean value from two experiments, where HLA-A2 stabilization units have been normalized to HIV (40 $\mu \mathrm{M}$ peptide) 

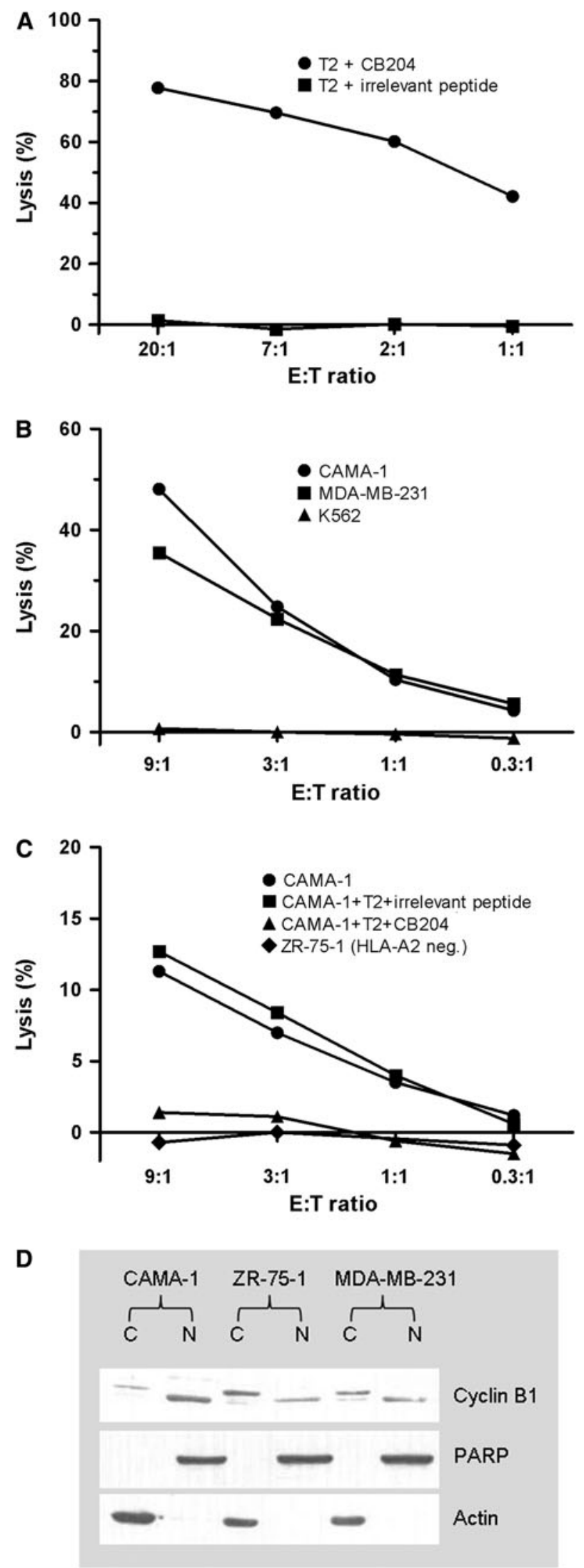

Fig. 2 Cytotoxic capacity of a CB204-specific CTL clone analyzed with a conventional $4-\mathrm{h}{ }^{51} \mathrm{Cr}$-release assay. E:T means effector to target ratio. The irrelevant peptide used is HIV-1 pol ${ }_{476-484}$. a Peptide-specific killing of T2 cells loaded with CB204. The experiment was performed in singlets. b Killing of the HLA-A2 ${ }^{+}$BC cell lines CAMA-1 and MDA-MB-231. K562 is an HLA ${ }^{-}$cell line, sensitive to NK-mediated killing. The experiment was performed in singlets, but it was repeated with similar results, however, with slightly lower lysis (max. lysis of CAMA-1 was $29 \%$, and of MDAMB-231 28\%). c Cold target inhibition assay with 20 times as many cold (non-radioactively labeled) T2 cells added. ZR-75-1 is an HLA$\mathrm{A} 2^{-}$BC cell line. The experiment was performed in singlets. d Subcellular fractionation and western blot analysis showing the subcellular location of cyclin B1 in the BC cancer cell lines used as targets in the ${ }^{51} \mathrm{Cr}$-release assay. PARP was used as loading control for the nuclear fraction $(\mathrm{N})$ and Actin for the cytoplasmic fraction $(\mathrm{C})$

was established, which was able to lyse T2 cells loaded with CB204, but not T2 cells loaded with an irrelevant HIV peptide (Fig. 2a). The CTL clone was also capable of killing two HLA-A2 ${ }^{+}$BC cell lines, but did not lyse the HLA $^{-}$, NK-sensitive cell line K562 (Fig. 2b). In addition, a cold target inhibition assay indicated peptide-specific and HLA-A2-restricted lysis, since the cold target cells presenting CB204 inhibited lysis of cancer cells, whereas the cold target cells presenting an irrelevant peptide did not (Fig. 2c). Furthermore, the CTL clone was not able to kill an HLA-A2 ${ }^{-}$BC cell line, again indicating HLA-A2restricted lysis (Fig. 2c). Fig. 2d shows that cyclin B1 was expressed in the three BC cell lines used as target cells. Cyclin B1 expression was observed in both cytoplasm and nucleus in the cell lines, although at different levels. This indicated overexpression of cyclin B1 in all three BC cell lines.

Altogether, there was strong evidence for processing and presentation of the CB204 peptide on the cell surface of BC cells in context of HLA molecules.

\section{Spontaneous T-cell responses against CB204}

Spontaneous T-cell reactivity against the CB204 peptide was analyzed in an IFN- $\gamma$ ELISPOT assay using PBLs from cancer patients. A high frequency of patients with BC, MM, or RCC hosted powerful spontaneous T-cell responses against the peptide (Fig. 3). In fact, seven out of ten BC patients, five out of six patients with MM, and four out of six RCC patients hosted a T-cell response against CB204. When PBMCs from healthy donors were tested, powerful and frequent responses were also observed (Fig. 3). 10 out of 11 healthy donors hosted a response against CB204.

Humoral immune responses against CB204

Serum samples from cancer patients and healthy donors were screened for anti-cyclin B1 responses. Cyclin B1 IgG 


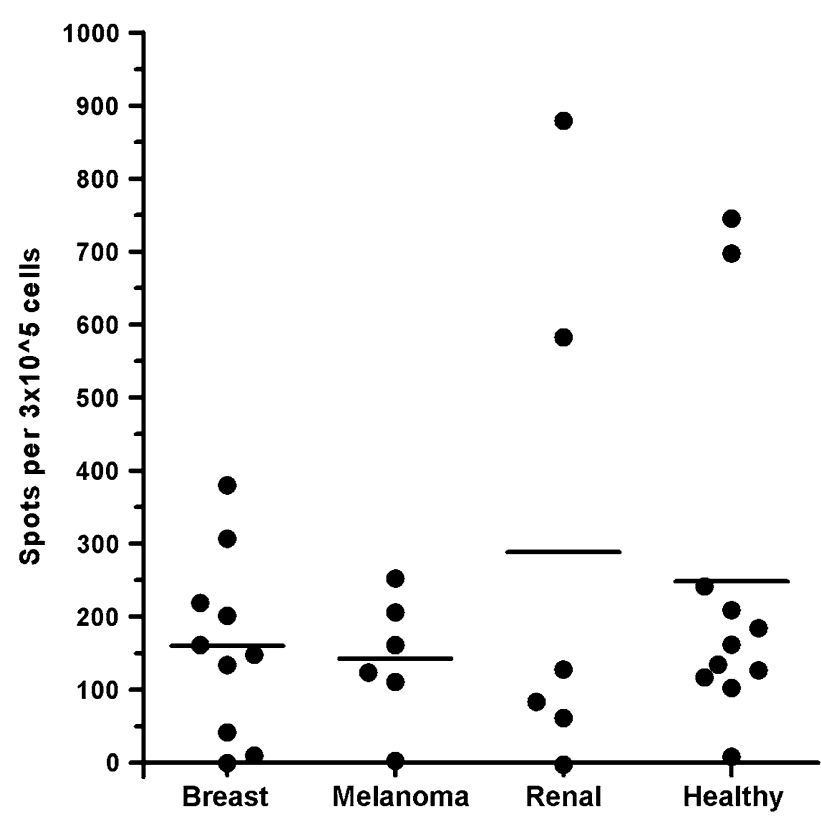

Fig. 3 T-cell responses against the CB204 peptide analyzed in an IFN- $\gamma$ ELISPOT assay. PBLs from ten patients with BC, six MM patients, six RCC patients, and PBMCs from eleven healthy donors were tested. The cell concentration was $3 \times 10^{5}$ cells per well, and the ELISPOT plates were incubated overnight. Measurements were performed in duplicates. Each dot represents a CB204-specific response, where the background has been subtracted. A response was defined as the average number of peptide-specific spots $\pm 1 / 2$ $\mathrm{SD}>25$ spots per $10^{5} \mathrm{PBLs} / \mathrm{PBMCs}$

could be detected in all patients and all healthy donors (Fig. 4). However, it was not possible to determine the objective cut-off point between the true antibody positive and negative individuals, because all samples were positive compared with the background control values. However, it is clear that anti-cyclin B1 responses were present in both cancer patients and healthy donors.

The level of anti-cyclin B1 antibody varied between the different individuals, but was similar between patients and healthy donors. In patients, the normalized absorbance $(405 \mathrm{~nm})$ ranged from 0.10 to 1.78 , and in healthy donors the range was from 0.38 to 1.34 .

\section{Discussion}

Due to the phenomenon of "immune escape", strategies are being developed that conceptually focus on minimizing the risk of immune escape by specifically targeting proteins that are important for the function, survival, and growth of cancer cells. Cyclin B1 represents such a protein, and Kao et al. [14] have described immunogenic, HLA-A2-restricted peptides derived from cyclin B1. These peptides were characterized by elution of peptides from cancer cells; thus, the expression of the peptides on the cell surface of cancer cells was firmly

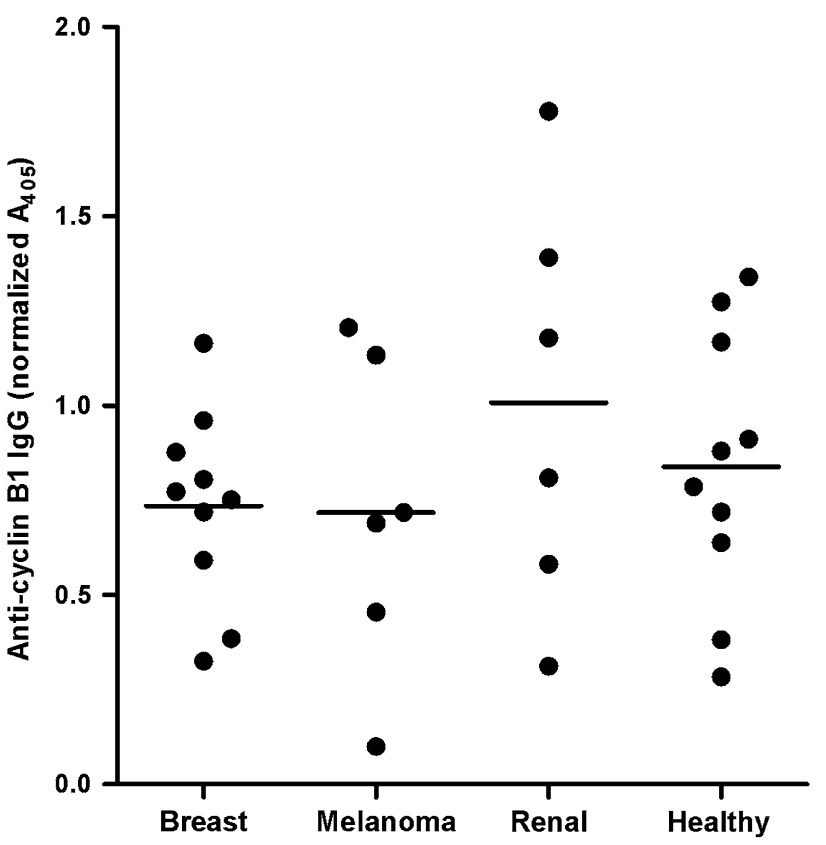

Fig. 4 Humoral responses against cyclin B1 analyzed by ELISA. Sera from ten patients with BC, six MM patients, six RCC patients, and ten healthy donors were tested. The cancer patients were the same as used in the analysis of CB204-specific T-cell responses (Fig. 3), but the healthy donors were different from those used for Fig. 3. The absorbance reading at $405 \mathrm{~nm}\left(\mathrm{~A}_{405}\right)$ corresponds to the amount of cyclin B1-specific antibody present in the serum. Each dot represents an anti-cyclin B1 response, where the background from uncoated wells has been subtracted. All samples have been normalized to a positive control serum. Four replicas were included for each sample

established. The epitopes identified were, however, of low affinity to HLA. In the present study, reverse immunology was used to identify a high-affinity CTL epitope. First, the amino acid sequence of the cyclin B1 protein was screened for the most probable HLA-A2 nonameric peptide epitopes using different CTL epitope prediction algorithms. The peptide CB204 was selected and an HLA stabilization assay showed that the peptide had very high affinity for HLA-A2. To verify the presence of the peptide on the cell surface of cancer cells, a CB204-specific CTL clone was established. The clone was able to lyse cyclin B1-overexpressing tumor cells in a peptide-specific and HLA-A2-restricted manner, showing that CB204 was presented in context of HLA-A2 molecules on the surface of cancer cells.

Additionally, we detected spontaneous T-cell responses against the CB204 peptide in $73 \%$ of the cancer patients tested and $90 \%$ of the healthy donors that were analyzed. These cells were most likely of an antigen-experienced phenotype, since they were able to produce IFN- $\gamma$ upon stimulation with the CB204 peptide alone. Furthermore, anti-cyclin B1 antibody responses were detected in all cancer patients and healthy donors analyzed, but it was, as mentioned, not possible to determine the cut-off between 
true positive and negative individuals in the ELISA assay. Nevertheless, frequent humoral responses against cyclin B1 were detected in both patients and healthy donors.

There were, however, no correlation between the T-cell responses and the antibody responses detected in the patients. Also, there was no correlation between patient disease progression/prior therapies/age and immune responses.

Cyclin B1-specific $\mathrm{T}$ cells and antibodies in cancer patients have been observed by others [14, 28]. In addition, Vella and co-workers [29] reported the presence of cyclin $\mathrm{B} 1$-specific $\mathrm{CD} 8^{+} \mathrm{T}$ cells in healthy donors. These $\mathrm{T}$ cells in healthy donors were also antigen-experienced based on their IFN- $\gamma$ production. They also detected anti-cyclin B1 antibodies $(\operatorname{IgG})$ in the healthy donors, corresponding with our results. Suzuki and coworkers [28] detected significantly lower levels of anti-cyclin B1 antibody in healthy donors than in cancer patients. This is contrary to our findings, where the levels were similar in all individuals. This difference may be explained by different assay protocols and use of different secondary antibodies. Suzuki and coworkers used an antibody detecting $\mathrm{IgM}, \mathrm{IgG}$, and IgA, whereas we only detected IgG. Maybe the predominant isotype in healthy donors is $\mathrm{IgG}$, and in cancer patients the other isotypes are dominant as well.

In addition to cyclin $\mathrm{B} 1$-specific $\mathrm{CD} 8^{+} \mathrm{T}$ cells and antibodies, Vella et al. also reported the presence of $\mathrm{CD}^{+}{ }^{+} \mathrm{T}$ cells in healthy donors. Thus, there seems to be extensive both humoral and cellular immune responses against cyclin B1 in healthy donors as well as cancer patients. This could indicate that anti-cancer immune therapy targeting cyclin B1 would be safe and not cause autoimmunity. Furthermore, the level of peptide-HLA complexes on the cell surface of normal cells is possibly too low to reach the threshold for immune detection. However, in cancer cells, overexpression of cyclin B1 leads to increased presentation of the peptide on the cell surface and thus T-cell recognition. This difference in expression would explain why cyclin B1-specific T cells in healthy donors do not cause autoimmunity, and why $\mathrm{T}$-cell responses against normal cells should not be expected in cancer patients treated with cyclin B1-targeted immunotherapy. However, the question as to why cyclin B1 - and some other TAA-elicits immune responses in normal healthy donors remains elusive.

In the study by Vella et al. [29], mice bearing cyclin B1overexpressing tumors were vaccinated using a proteinbased vaccination strategy. They observed induction of cyclin B1-specific $\mathrm{CD} 4^{+}$and $\mathrm{CD} 8^{+} \mathrm{T}$ cells and antibodies, lower tumor volume, increased survival of the mice, and no signs of autoimmunity. Although this was a mouse study and long-term effects could not be studied, it strongly supports cyclin B1 as an ideal target for anti-cancer vaccination and also indicates that it would be safe to induce an immune response directed against cyclin B1.
Besides indicating that cyclin B1-targeted anti-cancer immune therapy is safe, responses in healthy donors may also indicate that cyclin B1-targeted anti-cancer vaccination would have a higher efficacy due to a higher precursor frequency of cyclin B1-specific $\mathrm{T}$ cells. Rizzutto and coworkers [30] recently reported that, in mice, there is a correlation between the frequency of self-antigen-specific $\mathrm{CD}^{+}{ }^{+} \mathrm{T}$-cell precursors and the quality of the anti-cancer immune response. Mice challenged with the melanoma cell line B16F10 were adoptively administered different numbers of gp100-specific $\mathrm{CD} 8^{+} \mathrm{T}$ cells obtained from pmel-1 transgenic mice. Afterwards, the mice received three weekly vaccinations with plasmid encoding gp100. This experiment showed that gp100-specific $\mathrm{CD}^{+}{ }^{+}$T-cell precursor frequency was a significant predictor of treatment outcome. They observed both a better proliferation of autologous antigen-specific $\mathrm{T}$ cells in the mice, and also a higher frequency of poly-functional effector cells. In addition, the treated mice had a longer tumor-free survival period, and a higher frequency of memory cells 85 days after the last vaccination. If this translates to humans, cyclin B1 responses in healthy donors may be a good prognostic factor for successful anti-cancer vaccination. The fact that immune reactivity against cyclin B1 is observed in healthy donors could mean that cancer patients have a higher frequency of cyclin B1-specific $\mathrm{CD} 8^{+} \mathrm{T}$-cell precursors in the blood, in turn leading to a higher efficacy of cyclin B1-targeted anti-cancer vaccination.

In conclusion, cyclin B1 is a promising target for anticancer vaccination and maybe even for adoptive transfer of cyclin B1-specific T cells. Further studies should therefore be performed, aiming at characterizing cyclin B1-specific $\mathrm{T}$ cells in healthy donors further, as well as identifying CTL epitopes restricted to other HLA-alleles.

Acknowledgments This work was financially supported by The Danish Cancer Society, Danielsen Foundation, Danish Medical Research Council, the Novo Nordisk Foundation, the John and Birthe Meyer Foundation, and the Toyota Foundation. We would, additionally, like to thank Merete Jonassen for excellent technical assistance, Prof. A. Svejgaard and B.K. Jakobsen (Department of Clinical Immunology, Copenhagen University Hospital, Denmark) for HLA typing, and Özcan Buller Met for scientific discussions.

Open Access This article is distributed under the terms of the Creative Commons Attribution Noncommercial License which permits any noncommercial use, distribution, and reproduction in any medium, provided the original author(s) and source are credited.

\section{References}

1. Novellino L, Castelli C, Parmiani G (2005) A listing of human tumor antigens recognized by T cells: March 2004 update. Cancer Immunol Immunother 54:187-207 
2. Nestle FO, Alijagic S, Gilliet M, Sun Y, Grabbe S, Dummer R, Burg G, Schadendorf D (1998) Vaccination of melanoma patients with peptide- or tumor lysate-pulsed dendritic cells. Nat Med 4:328-332

3. Rosenberg SA, Yang JC, Schwartzentruber DJ, Hwu P, Marincola FM, Topalian SL, Restifo NP, Dudley ME, Schwarz SL, Spiess PJ, Wunderlich JR, Parkhurst MR, Kawakami Y, Seipp CA, Einhorn JH, White DE (1998) Immunologic and therapeutic evaluation of a synthetic peptide vaccine for the treatment of patients with metastatic melanoma. Nat Med 4:321-327

4. Wobser M, Keikavoussi P, Kunzmann V, Weininger M, Andersen MH, Becker JC (2006) Complete remission of liver metastasis of pancreatic cancer under vaccination with a HLA-A2 restricted peptide derived from the universal tumor antigen survivin. Cancer Immunol Immunother 55:1294-1298

5. Riker A, Cormier J, Panelli M, Kammula U, Wang E, Abati A, Fetsch P, Lee KH, Steinberg S, Rosenberg S, Marincola F (1999) Immune selection after antigen-specific immunotherapy of melanoma. Surgery 126:112-120

6. Andersen MH, Svane IM, Becker JC, thor Straten P (2007) The universal character of the tumor-associated antigen survivin. Clin Cancer Res 13:5991-5994

7. Vonderheide RH (2008) Prospects and challenges of building a cancer vaccine targeting telomerase. Biochimie 90:173-180

8. Yu M, Zhan Q, Finn OJ (2002) Immune recognition of cyclin B1 as a tumor antigen is a result of its overexpression in human tumors that is caused by non-functional p53. Mol Immunol 38:981-987

9. Egloff AM, Vella LA, Finn OJ (2006) Cyclin B1 and other cyclins as tumor antigens in immunosurveillance and immunotherapy of cancer. Cancer Res 66:6-9

10. Kawamoto H, Koizumi H, Uchikoshi T (1997) Expression of the G2-M checkpoint regulators cyclin B1 and cdc2 in nonmalignant and malignant human breast lesions: immunocytochemical and quantitative image analyses. Am J Pathol 150:15-23

11. Tran TA, Ross JS, Carlson JA, Mihm MC Jr (1998) Mitotic cyclins and cyclin-dependent kinases in melanocytic lesions. Hum Pathol 29:1085-1090

12. Ikuerowo SO, Kuczyk MA, Mengel M, van der HE, Shittu OB, Vaske B, Jonas U, Machtens S, Serth J (2006) Alteration of subcellular and cellular expression patterns of cyclin B1 in renal cell carcinoma is significantly related to clinical progression and survival of patients. Int J Cancer 119:867-874

13. Ersvaer E, Zhang JY, McCormack E, Olsnes A, Anensen N, Tan EM, Gjertsen BT, Bruserud O (2007) Cyclin B1 is commonly expressed in the cytoplasm of primary human acute myelogenous leukemia cells and serves as a leukemia-associated antigen associated with autoantibody response in a subset of patients. Eur J Haematol 79:210-225

14. Kao H, Marto JA, Hoffmann TK, Shabanowitz J, Finkelstein SD, Whiteside TL, Hunt DF, Finn OJ (2001) Identification of cyclin B1 as a shared human epithelial tumor-associated antigen recognized by T cells. J Exp Med 194:1313-1323

15. Rammensee HG, Bachmann J, Emmerich NPN, Bachor OA, Stevanovic S (1999) SYFPEITHI: database for MHC ligands and peptide motifs. Immunogenetics 50:213-219

16. Buus S, Lauemoller SL, Worning P, Kesmir C, Frimurer T, Corbet S, Fomsgaard A, Hilden J, Holm A, Brunak S (2003) Sensitive quantitative predictions of peptide-MHC binding by a 'Query by Committee' artificial neural network approach. Tissue Antigens 62:378-384

17. Nielsen M, Lundegaard C, Worning P, Lauemoller SL, Lamberth K, Buus S, Brunak S, Lund O (2003) Reliable prediction of T-cell epitopes using neural networks with novel sequence representations. Protein Sci 12:1007-1017

18. Parker KC, Bednarek MA, Coligan JE (1994) Scheme for ranking potential HLA-A2 binding peptides based on independent binding of individual peptide side-chains. J Immunol 152:163-175

19. Elvin J, Potter C, Elliott T, Cerundolo V, Townsend A (1993) A method to quantify binding of unlabeled peptides to class I MHC molecules and detect their allele specificity. J Immunol Methods 158:161-171

20. Andersen MH, Tan L, Sondergaard I, Zeuthen J, Elliott T, Haurum JS (2000) Poor correspondence between predicted and experimental binding of peptides to class I MHC molecules. Tissue Antigens 55:519-531

21. Andersen MH, Bonfill JE, Neisig A, Arsequell G, Sondergaard I, Valencia G, Neefjes J, Zeuthen J, Elliott T, Haurum JS (1999) Phosphorylated peptides can be transported by TAP molecules, presented by class I MHC molecules, and recognized by phosphopeptide-specific CTL. J Immunol 163:3812-3818

22. Krejsgaard T, Vetter-Kauczok CS, Woetmann A, Lovato P, Labuda T, Eriksen KW, Zhang Q, Becker JC, Odum N (2006) Jak3- and JNK-dependent vascular endothelial growth factor expression in cutaneous T-cell lymphoma. Leukemia 20:17591766

23. Andersen MH, Svane IM, Kvistborg P, Nielsen OJ, Balslev E, Reker S, Becker JC, thor Straten P (2005) Immunogenicity of Bcl-2 in patients with cancer. Blood 105:728-734

24. McCutcheon M, Wehner N, Wensky A, Kushner M, Doan S, Hsiao L, Calabresi P, Ha T, Tran TV, Tate KM, Winkelhake J, Spack EG (1997) A sensitive ELISPOT assay to detect low-frequency human T lymphocytes. J Immunol Methods 210:149-166

25. Trepiakas R, Berntsen A, Hadrup SR, Bjorn J, Geertsen PF, thor Straten P, Andersen MH, Pedersen AE, Soleimani A, Lorentzen T, Johansen JS, Svane IM (2010) Vaccination with autologous dendritic cells pulsed with multiple tumor antigens for treatment of patients with malignant melanoma: results from a phase I/II trial. Cytotherapy 12(6):721-734

26. Berntsen A, Trepiakas R, Wenandy L, Geertsen PF, thor Straten $\mathrm{P}$, Andersen MH, Pedersen AE, Claesson MH, Lorentzen T, Johansen JS, Svane IM (2008) Therapeutic dendritic cell vaccination of patients with metastatic renal cell carcinoma: a clinical phase 1/2 trial. J Immunother 31:771-780

27. Svane IM, Pedersen AE, Johansen JS, Johnsen HE, Nielsen D, Kamby C, Ottesen S, Balslev E, Gaarsdal E, Nikolajsen K, Claesson MH (2007) Vaccination with p53 peptide-pulsed dendritic cells is associated with disease stabilization in patients with p53 expressing advanced breast cancer; monitoring of serum YKL-40 and IL-6 as response biomarkers. Cancer Immunol Immunother 56:1485-1499

28. Suzuki H, Graziano DF, McKolanis J, Finn OJ (2005) T celldependent antibody responses against aberrantly expressed cyclin B1 protein in patients with cancer and premalignant disease. Clin Cancer Res 11:1521-1526

29. Vella LA, Yu M, Fuhrmann SR, El-Amine M, Epperson DE, Finn OJ (2009) Healthy individuals have T-cell and antibody responses to the tumor antigen cyclin B1 that when elicited in mice protect from cancer. Proc Natl Acad Sci USA 106:14010-14015

30. Rizzuto GA, Merghoub T, Hirschhorn-Cymerman D, Liu C, Lesokhin AM, Sahawneh D, Zhong H, Panageas KS, Perales MA, tan-Bonnet G, Wolchok JD, Houghton AN (2009) Self-antigenspecific CD8 $+\mathrm{T}$ cell precursor frequency determines the quality of the antitumor immune response. J Exp Med 206:849-866 